
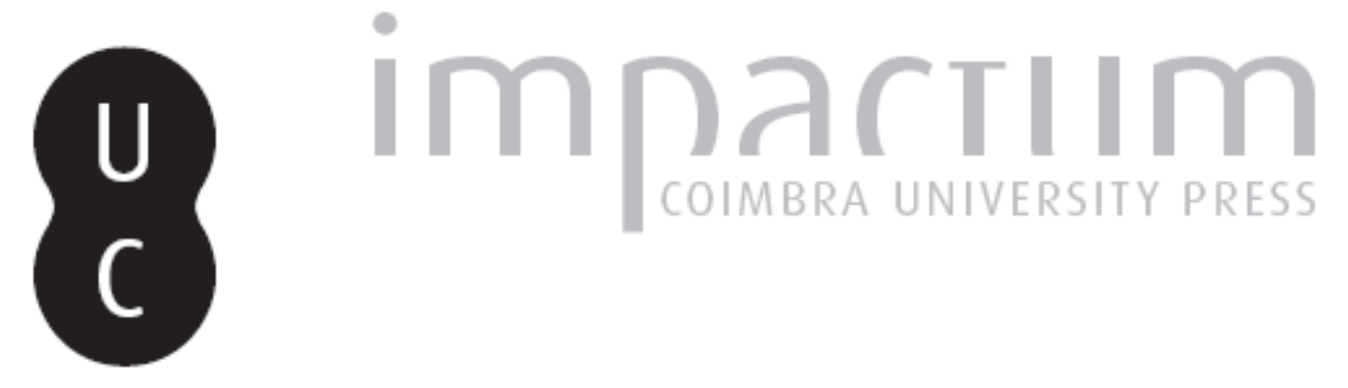

\title{
Giorgio Grassi e a arquitectura portuguesa
}

Autor(es): Rodrigues, José Miguel

Publicado por: Imprensa da Universidade de Coimbra

URL persistente:

URl:http://hdl.handle.net/10316.2/44966

DOI:

DOI:https://doi.org/10.14195/0870-8584_12_3

Accessed : $\quad$ 26-Apr-2023 13:09:27

A navegação consulta e descarregamento dos títulos inseridos nas Bibliotecas Digitais UC Digitalis, UC Pombalina e UC Impactum, pressupõem a aceitação plena e sem reservas dos Termos e Condições de Uso destas Bibliotecas Digitais, disponíveis em https://digitalis.uc.pt/pt-pt/termos.

Conforme exposto nos referidos Termos e Condições de Uso, o descarregamento de títulos de acesso restrito requer uma licença válida de autorização devendo o utilizador aceder ao(s) documento(s) a partir de um endereço de IP da instituição detentora da supramencionada licença.

Ao utilizador é apenas permitido o descarregamento para uso pessoal, pelo que o emprego do(s) título(s) descarregado(s) para outro fim, designadamente comercial, carece de autorização do respetivo autor ou editor da obra.

Na medida em que todas as obras da UC Digitalis se encontram protegidas pelo Código do Direito de Autor e Direitos Conexos e demais legislação aplicável, toda a cópia, parcial ou total, deste documento, nos casos em que é legalmente admitida, deverá conter ou fazer-se acompanhar por este aviso.

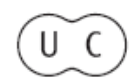




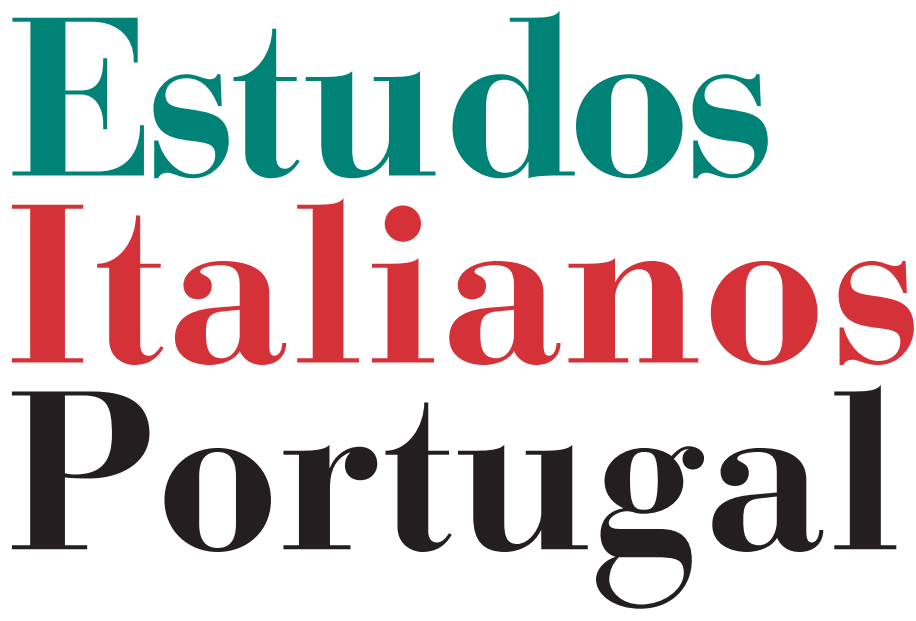

Instituto

Italiano

de Cultura

de Lisboa

Nova Série

No 12

2017 


\title{
GIORGIO GRASSI \\ E A ARQUITECTURA PORTUGUESA
}

\author{
José Miguel Rodrigues*
}

\section{CASABELLA-CONTINUITÀ}

ERnesto Nathan Rogers é o professor da escola de arquitectura de Milão que primeiro marcou a formação e a linha de orientação que Giorgio Grassi tomou para si e para o seu trabalho até hoje. Ernesto Rogers era, certamente, uma personagem. Além de professor, era arquitecto (co-fundador dos BBPR) e director de Casabella-Continuità (na verdade o "sufixo" continuidade foi um acrescento de Rogers, quando aceitou o encargo de dirigir a revista Casabella). Grassi conta que a disciplina de Rogers ficava tradicionalmente para o fim do curso e que, com o trabalho que faziam para essa cadeira, os estudantes concluíam o seu percurso de aprendizagem ${ }^{1}$. Os melhores publicavam uma versão reelaborada dos seus trabalhos na revista de Rogers. Assim foi com Giorgio Gras$\mathrm{si}^{2}$ que se iniciou em Casabella-Continuità com "Imagens de

* Porto, 1970. Arquitecto e Professor na FAUP. Publicou O mundo ordenado $e$ acessivel das formas da arquitectura. Tradição clássica e movimento moderno na arquitectura portuguesa (tese de doutoramento defendida em 2007). É coordenador e tradutor do projecto de tradução Giorgio Grassi, opera omnia sic. HYPERLINK "mailto:jrodrigues@arq.up.pt" It "_blank" jrodrigues@arq.up.pt

${ }^{1}$ Giorgio Grassi, Una vita da architetto, Milano, Franco Angeli, 2008, p. 17.

${ }^{2}$ A propósito do início da relação Rossi-Grassi, este último refere como "entretanto, também tinha começado a trabalhar em Casabella, onde além do mais nasceu a amizade com Aldo Rossi” (ib., p. 18). 
Berlage" 3 - ensaio nunca mais publicado nas suas antologias de escritos.

Do pequeno ensaio iniciático de Grassi não temos, que se saiba, qualquer eco em Portugal. Da revista Casabella e de Rogers, seu editor, temos, no entanto, uma significativa ressonância, motivada pela controvérsia Rogers-Reyner Banham, que ficou conhecida pela réplica de Rogers "ao guardiāo dos frigoríficos", a propósito de um editorial de Banham que acusava os arquitectos italianos de desistirem das causas da modernidade. Referimo-nos ao modo impressionantemente informado como Nuno Portas (editor da revista portuguesa Arquitectura) nos dava notícia da contenda, ao mesmo tempo que tomava claramente partido a favor de Rogers:

Sob o subtítulo de "A retirada italiana da arquitectura moderna", Reyner Banham, conhecido editor da A. R., tece um violento e mal informado ataque ao sector dos arquitectos transalpinos que por diferentes vias retomam certos aspectos temáticos ou formais dos pioneiros do movimento moderno. As posiçôes demasiado dogmáticas do crítico britânico não lhe permitem discernir as diferenças entre um Moretti ou um Ponti e um Figgini ou um Raineri. De passagem, o próprio Terragni é aliás arrumado como académico. Este tipo de crítica de um ponto de vista algo impositorial, como se o movimento moderno fosse qualquer coisa de estático, ou se alguém detivesse o segredo da sua integridade, servem sobretudo para agravar equívocos. - Resposta de E. N. Rogers, no editorial do n. ${ }^{\circ} 228$ de Casabella. ${ }^{4}$

Talvez por isso, ou seja, talvez influenciado por isto, em 1960 Távora escreveu no seu diário de viagem: "O tempo, em Taliesin, joga a favor da arquitectura e da paisagem, o que creio não acontece em noventa e nove por cento da arquitectura moderna. / Vi há tempo a casa de Gropius em Lincoln:

\footnotetext{
${ }^{3}$ Giorgio Grassi, "Immagine di Berlage", Casabella, 249, 1961, pp. 39-43.

${ }^{4}$ Nuno Portas, "Neoliberty", Arquitectura, 65, 1959, p. 54.
} 
quando vi Taliesin, a casa de Gropius pareceu-me um frigorífico pousado numa colina!"5.

\section{SAN ROCCO}

O milieu arquitectónico português conheceu Aldo Rossi antes de Giorgio Grassi, evidentemente, através da leitura de L'architettura della città (1966). A comparação é importante porque, como se viu, ambos aprenderam com Rogers, mas também, como se verá, na medida em que ambos seguiram caminhos distintos, pese embora a origem comum. Nesta distinção, compreender-se-á a importância de Grassi para a arquitectura portuguesa contemporânea, seja de modo directo e evidenciável, seja de modo indirecto, embora reconhecível, empírica e teoricamente. Em 1969, por exemplo, Nuno Portas publicava $A$ cidade como arquitectura, um título deliberadamente invertido a partir de Rossi ${ }^{6}$. A problemática da cidade e da arquitectura enquanto domínios - complementares ou não - da actividade dos arquitectos entrava, assim, no debate arquitectónico em Portugal.

Em meados dos anos sessenta, convém lembrar, Giorgio Grassi e Aldo Rossi partilharam atelier, tendo colaborado em dois concursos. A relação entre ambos é descrita por Grassi como "a experiência intelectualmente mais importante daquele período [...], ainda o período da minha aprendizagem. Uma experiência, de resto, que não podia durar muito mais, por incompatibilidade de feitios, digamos assim, que desde o princípio se tinha manifestado

${ }^{5}$ Regulamento do Prémio Távora, Porto, 2005, s. p.; Fernando Távora, "Extractos do diário de viagem" [1960], Fernando Távora, Opera completa, ed. Antonio Esposito, Giovanni Leoni, Milano, Electa, 2005, p. 307. Ver, mais recentemente, Fernando Távora, Diário de "bordo", vol. 1, Diário de "bordo". Facsímile, coordenador Álvaro Siza, Porto, Casa da Arquitectura / Fundação Instituto Arquitecto Marques da Silva, 2012, p. 237.

${ }^{6}$ Nuno Portas, A cidade como arquitectura, Lisboa, Livros Horizonte, 2007, pp. 205-206. 
como extremamente fecunda e ao mesmo tempo incrivelmente destrutiva"7.

O projecto para San Rocco (1966), em co-autoria, evidencia os dois caminhos distintos (divergentes, mas não em sentidos opostos) que, a partir do mesmo ponto de partida (Rogers), Rossi e Grassi desenharam para a sua arquitectura. É interessante, a este propósito, cotejar o modo como cada um deles o publicou nas respectivas monografias. A mesma maqueta (muito provavelmente de gesso), o mesmo desenho em planta (com "sombras") e comentários, embora distintos, absolutamente complementares.

Grassi enfatiza o sentido da repetição no projecto, ao passo que Rossi identifica as referências para os grandes pátios do movimento moderno de Berlim ou Viena: referências que atravessam a história da arquitectura e da cidade, mas que se confrontam sempre com as características particulares e locais de um modo de construção secular na Lombardia. Instado a comentar a dualidade formalismo-realismo, Grassi recordará, no entanto, que há projectos que têm o ar demasiado recherché de fragmentos (aquele ar que para mim é também o ponto débil de San Rocco de Monza) ${ }^{8}$.

Se observarmos o projecto procurando perscrutar este ponto débil, não será difícil supor que se refere a um dos seguintes aspectos, se não a todos eles concomitantemente: 1) a torção (subtil, mas expressiva, do ponto de vista formal) que provoca um desencontro entre as duas malhas que compóem o projecto, criando uma linha de tensão na composição; 2) o modo como os pátios de escala menor se desconstroem, a certo ponto da proposta, para permanecerem como que em aberto; ou, ainda: 3) o modo como um dos três pátios, o

${ }^{7}$ Giorgio Grassi, Una vita da architetto, p. 20. Nota do autor: esta e as demais traduções que fazem parte integrante deste ensaio são da nossa responsabilidade, não dispensando, por isso, a leitura das passagens na língua em que foram escritas (sempre referenciadas às obras originais em nota de rodapé).

${ }^{8}$ Id., Scritti scelti. 1965-1999, Milano, Franco Angeli, 2000, p. 175. 
de maior dimensão, que o projecto excepcionalmente contempla, também excepcionalmente se individualiza (o pátio isola-se e roda ligeiramente em relação às duas direcções que determinam a geometria da composição). A questão é complexa e dá que pensar. Neste contexto, importa apenas darmo-nos conta de que Grassi tem uma visão da forma e dos seus perigos - o formalismo - mais temerária que Rossi ou, observando a questão do prisma oposto, que Rossi tem uma visão mais livre da forma e das suas virtualidades. Grassi partilha uma visão menos optimista (e por isso muitas vezes considerada mais rígida) das virtualidades que as formas isoladas pressupõem (o isolamento não é uma qualidade a que Grassi dê grande valor, como se pode verificar em toda a sua obra).

A afinidade não analógica entre as arquitecturas de Rossi e Grassi é importante, na medida em que nos permitirá compreender o interesse que a arquitectura de Grassi despertará na Escola do Porto. A pequena mas significativa diferença no modo como ambos olham distintamente para o projecto de San Rocco constitui um sinal precoce, como se toda a obra de Grassi posterior fosse a continuação de um dos possíveis caminhos que a obra inicial de Rossi, apenas em parte (no Gallaratese ou em Fagnano Olona, por exemplo), deixava antecipar e que Grassi parece ter continuado depois e até hoje.

\section{A CONSTRUÇÃo LÓGICA DA ARQUitectura VS A ARQUiTECTU- RA DA CIDADE}

Em 1967, Grassi publicaria La costruzione logica dell'architettura 9 um ano depois de Rossi ter editado L'architettura della città ${ }^{10}$. Da mesma feita, desde logo é possível estabelecer um quadro de semelhanças e diferenças que ajudaria a

\footnotetext{
${ }^{9}$ Venezia, Polis, Marsilio, 1967.

${ }^{10}$ Padova, Marsilio, 1966.
} 
compreender o enorme sucesso do livro de Rossi, também em Portugal, onde foi objecto de tradução (1977) por José Charters Monteiro, co-autor, em parceria com José Sousa Martins, de um projecto para o conjunto da Bela Vista em Setúbal, envolvendo o próprio Rossi (1974).

La costruzione logica dell'architettura é, como o título sem ambiguidades o anuncia, uma teorização sobre a construção da arquitectura enquanto artefacto humano, envolvendo decisóes e escolhas eminentemente arquitectónicas, donde também decorre o seu carácter lógico. Em termos muito simples, o livro de Grassi trata daquela parte maior da arquitectura, uma vez que, como disse Loos, amplamente citado no livro, apenas uma sua pequena parte (o túmulo e o monumento) é arte. O livro de Rossi, no entanto, também não se pode dizer que tenha elegido o monumento, em detrimento do consuetudinário que é a casa para todos e para cada um de nós.

Este primeiro livro de Grassi (depois profundamente reescrito numa segunda edição) ${ }^{11}$ não só não teve o impacto do de Rossi, como, sobretudo, cremos, não tinha ainda encontrado o suporte construído (isto é, uma obra construída com a visibilidade da obra de Rossi), de forma que lhe fosse permitido alcançar, no final dos anos sessenta, o estatuto de teoria de projecto que, sem dificuldade, Rossi poderia reclamar para si com L'architettura della città.

$\mathrm{O}$ livro de Grassi, porém, foi muito bem acolhido por um grupo de arquitectos de Barcelona (particularmente Carlos Martí Arís), tendo sido objecto de uma tradução para catalão que anunciava a sua importância fora do contexto italiano.

Grassi continuou no entanto a projectar e a construir (embora pouco) e, o que é notável, continuou também a encontrar espaço para publicar os seus projectos (muitas vezes tão só desenhos). Carlos Machado refere precisamente essa experiência iniciática ao folhear uma publicação em que os desenhos de Grassi sobressaiam, pelo carácter ascético, por

\footnotetext{
${ }^{11}$ Giorgio Grassi, La costruzione logica dell'architettura, Milano, Franco Angeli, 2008.
} 
entre a exuberância formal que caracterizava as diversas propostas ditas pós-modernas que, nos anos oitenta e noventa, de forma hegemónica dominavam o meio editorial.

\section{A ARQUiteCTURA COMO OFÍCIO VS AUTOBIOGRAFIA CIENTÍFICA}

Em 1979, Grassi antecipava a saída do livro seguinte de Rossi, que seria o último - a sua Autobiografia scientifica - com a publicação de L'architettura come mestiere e altri scritti. Neste caso, o livro de Grassi foi imediatamente traduzido para espanhol, numa colecção dirigida por Ignasi de Solà-Morales. Josep Linazasoro escreveu uma introdução crítica ao livro e ao seu autor intitulada "La crítica del silencio: Giorgio Grassi y los 'arquitectos inoportunos" "12.

Este segundo livro de Grassi teve já uma recepção muito significativa, também na Escola do Porto (impacto que o autor destas linhas pôde testemunhar, de forma directa, enquanto estudante da recém-criada FAUP, Faculdade de Arquitectura da Universidade do Porto). O livro - sobretudo na versão espanhola - era tão requisitado na pequena biblioteca da FAUP que 'desapareceu', ainda assim constando hoje no catálogo da biblioteca. O seu texto mais notado (e, também, aquele de título mais apocalíptico) foi, evidentemente, "Arquitettura lingua morta", 1 e 2 (isto é, em duas versões muito diferentes, embora complementares, como já nessa versão do livro se podia depreender e ler). De facto, "Arquitettura lingua morta", 2, mais não faz do que esclarecer o tom apocalíptico do título e, na verdade, procurando explicar algumas das razóes que justificavam aquilo que aí se dizia, suavizava as consequências da sua análise demolidora da realidade contemporânea para a disciplina: ou seja, para o ofício (como se traduziu para espanhol numa opção terminológica que permanece até hoje o cânone) ou, para o mes-

${ }^{12}$ Id., La arquitectura como oficio y otros escritos, Barcelona, Gustavo Gili, 1980, pp. $7-17$. 
ter, como se poderia também ter traduzido, sem dificuldade, para português.

Por sua vez, Autobiografia scientifica é um livro eloquente e lapidar. No entender de muitos, um livro em que Rossi se afasta da importância da noção de tipo, enquanto categoria indispensável ao pensamento arquitectónico, para afirmar a tonalidade poética de toda a arquitectura que nos toca. Na nossa perspectiva, é algo que já havia anunciado em L'architettura della città. A crítica arquitectónica e os leitores desatentos (os leitores dos títulos dos livros de arquitectura que não escasseiam nunca) entendeu, porém, que Rossi invertia a marcha e a verdade é que a obra construída de Rossi sofre neste ponto uma inflexão, a nosso ver ainda inteiramente por explicar, e que aparentemente corrobora esta perspectiva, por assim dizer, mais desatenta ou simplista. Neste contexto, L'architettura come mestiere parece que segue na direç̧ão oposta de Rossi, nesse momento dos anos oitenta (parafraseando uma imagem bernhardiana cara a Grassi), o que neste caso significa que Grassi segue a direcção que parecia orientar Rossi até àquele momento.

Ao contrário, porém, do que uma leitura simplista poderia levar a crer, embora Rossi não queira abandonar (nem nunca tenha chegado mesmo a abandonar) a noção de tipo, a verdade é que Grassi tempera a rigidez da ideia de tipo (que Quatremère de Quincy sinaliza) e reconvoca, em seu auxílio, a noção de modelo (que o mesmo Quatremère desmerece) ${ }^{13}$. Os modelos passarão assim a fazer parte integrante da teoria de projecto de Grassi e a palavra jamais será abandonada na análise da sua própria obra, ao ponto de, no final, se perceber como 'a boa arquitectura', em seu entender, depende mais da observação

13 "O modelo entendido na execução prática da arte é um objecto que se deve repetir tal e qual ele é; o tipo, pelo contrário, é um objecto a partir do qual cada um pode conceber obras que não se pareçam entre si", s. v. "Type" in Quatremère de Quincy, Dictionnaire historique de l'architecture [...], vol. 2, Paris, Librarie d'Arien le Clère, 1832, citado por Carlos Martí Arís em Las variaciones de la identidad. Ensayo sobre el tipo en arquitectura, Barcelona, Ediciones del Serbal, 1993, p. 142. 
atenta, com os olhos de quem faz, dirá, dos modelos, do que propriamente da conceptualização rigorosa e científica dos tipos que, numa palavra que claramente evita, a disciplina designa enquanto a tipologia.

\section{Primeira conferênCia no Porto: Groningen (1990)}

Em 1990, Grassi fará a primeira viagem ao Porto para uma conferência sobre o seu trabalho inserida no ciclo Discursos de Arquitectura ${ }^{14}$. Terá sido através desta conferência que a arquitectura de Grassi se deu a conhecer, pela primeira vez, ao milieu arquitectónico do Porto, pelo menos de modo informado, pese embora ter, desde logo, advertido que o seu modo de trabalhar era bastante elementar, não necessitando por isso de muitas explicações. A verdade é que o início da conferência foi dedicado, precisamente, à explicitação de um princípio arquitectónico - a crítica à cidade do século XIX e ao seu legado - que, naquela ocasião, expôs e procurou evidenciar através dos seus projectos que coerentemente propunham o regresso, sem mimetismos nem nostalgia, à cidade anterior ao século XIX, antecipando uma ideia que viria a marcar o modo como observava o seu próprio trabalho, isto é, a ideia de projectos para a cidade antiga (no sentido de cidade como era antes do século XIX).

A conferência concluiu-se com um projecto para a autarquia do município de Gavà, na Catalunha (em co-autoria com Antonio Armesto e Carlos Martí). Grassi explicou, com particular eloquência, este último projecto. Gavà era um pe-

\footnotetext{
${ }^{14}$ Carlos Machado foi o responsável pela sua apresentação. Posteriormente, dedicou boa parte do seu Relatório, no âmbito das provas de Aptidão Pedagógica e Capacidade Científica realizadas em Outubro de 1992, aos projectos, obras e escritos de Grassi (Trabalho de sintese, Relatório para uma aula, Curriculum Vitae, Porto, FAUP, 1992, policopiado). Na conferência de 2015, em conjunto com Eduardo Souto Moura, comentou Leon Battista Alberti e a arquitectura romana no contexto do lançamento da tradução para português de Giorgio Grassi, Alberti e a arquitectura romana, trad. José Miguel Rodrigues, Porto, FIMS, Afrontamento, 2014.
} 
queno município junto ao mar, em crescimento acelerado, à procura de refundar a sua identidade. Ser contextual, no sentido de aproximação ao existente, não é aqui caminho. Sendo a construção recente especulativa e excessiva, de acordo com a leitura de Grassi a excepcionalidade exigida pelo programa (a casa comum dos cidadãos) obrigava a uma inversão de escalas, isto é, perante os excessos das volumetrias envolventes, era o edifício da autarquia que tinha que ser baixo para, assim, se evidenciar no meio da altura excessiva do contexto. Ser 'baixo' é, aqui, a condição de excepcionalidade exigida pelo programa de um equipamento para todos. Através do seu projecto, Grassi dava a ver como ser contextual implica por vezes contrariar o próprio contexto, uma perspectiva importante naquele momento em que o lugar-comum de que a ideia está no sítio ainda não tinha sido devidamente temperado com a ideia, também de Siza, de que "o sítio vale pelo que é e pelo que pode ou deseja ser - coisas talvez opostas, mas nunca sem relação" 15 .

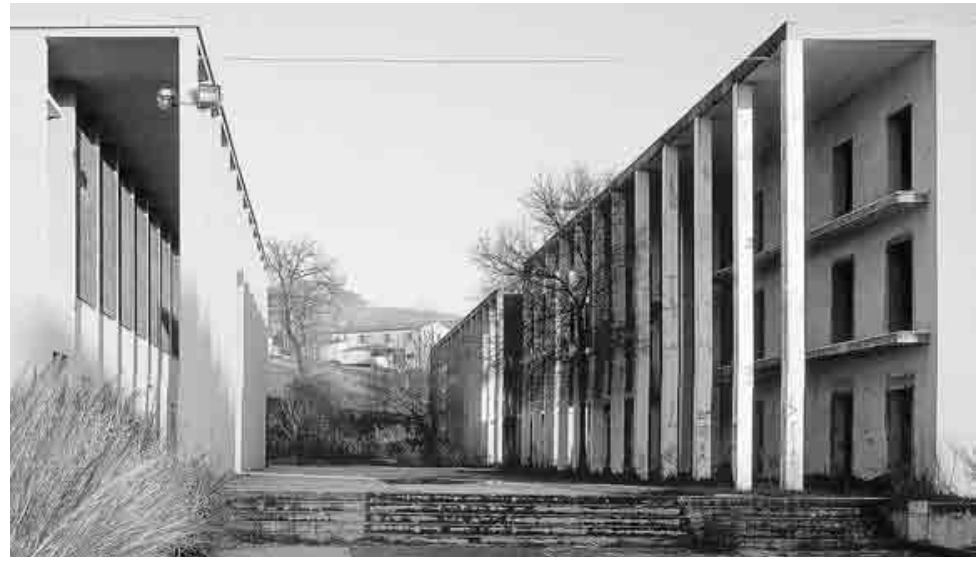

Fig. 1 Giorgio Grassi, Residência de estudantes, Chieti, 1976. (C) Giorgio Grassi.

O projecto de Grassi que no entanto terá ficado impresso na memória dos que assistiram à conferência foi sem dúvi-

${ }^{15}$ Álvaro Siza, 01 textos, Porto, Civilização, p. 27. 
da a biblioteca de Groningen. Até àquela conferência, a sua obra mais debatida era a residência de estudantes de Chieti, evidentemente, pelo pórtico da ordem monumental que resolve os pátios da estrutura em pente da residência. Esse pórtico, excessivamente alto, como viria a dizer das janelas do Charlottenhof de Schinkel em Potsdam, isto é, trilhando o

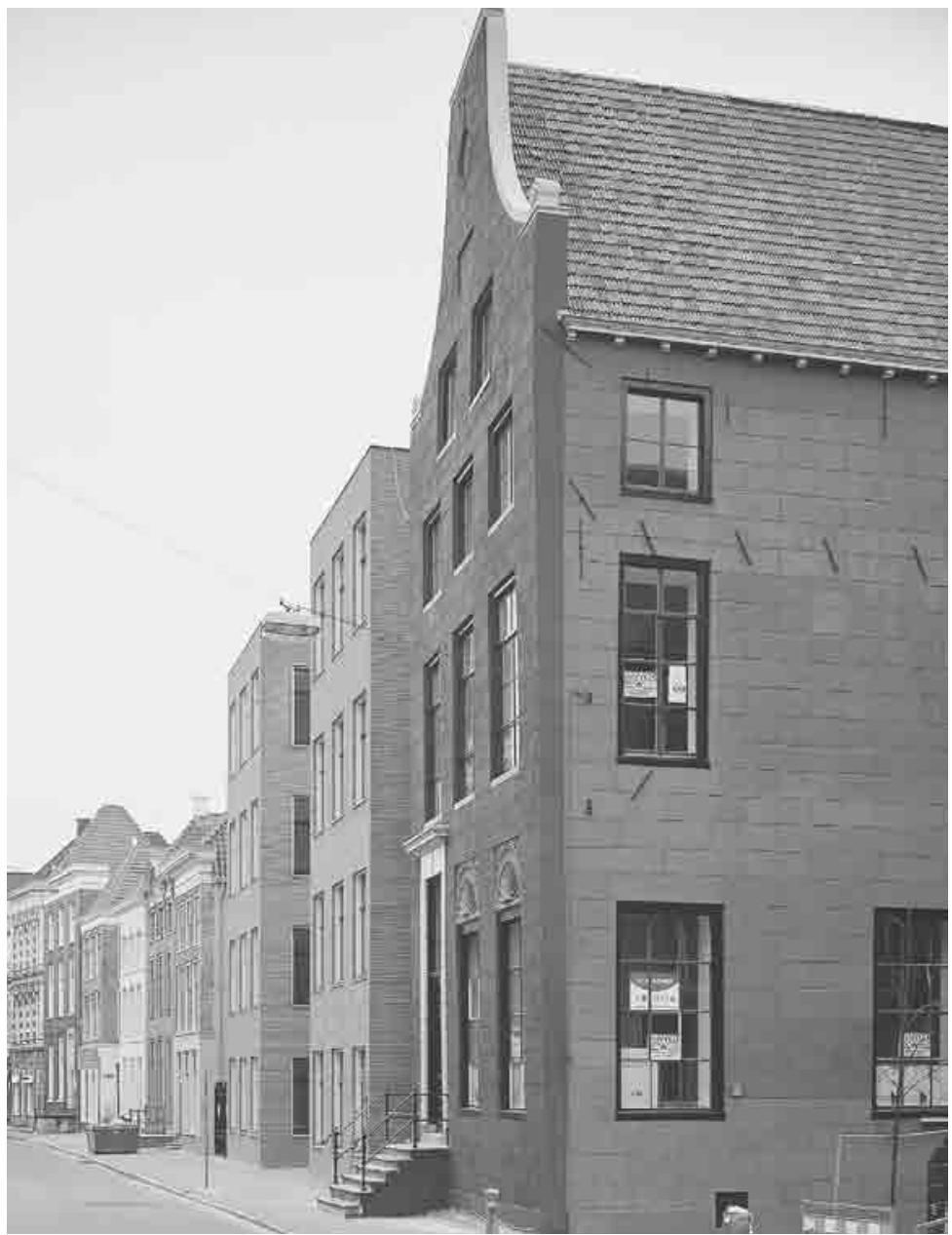

Fig. 2 Giorgio Grassi, Biblioteca Pública, Groningen, 1989. (C) Giorgio Grassi. 
caminho dos arquitectos neoclássicos, foi lido pelos seus detractores como uma citação directa da 'arquitectura fascista' e como tal indício de autoritarismo, por osmose, também arquitectónico. A biblioteca de Groningen - que Grassi explicou brilhantemente com base em exemplos existentes in situ na Groningen antiga (as implantaçóes à face da rua e as que, como as igrejas católicas, por razóes prescritivas, tinham que se manter recuadas) - dava a ver uma nova perspectiva sobre a aplicação prática da sua teoria (mais fácil de convencer do que a sua obra), num projecto que, com grande maestria e muito risco, combinava abstracção necessária com sentido preciso da importância do ornamento arquitectónico recorrendo a citaçôes inquestionavelmente classicizantes (explicadas com tradições locais de construção de molduras e outros elementos do vocabulário clássico em madeira na Holanda), na linha do Adolf Loos da casa Rufer (em especial, a réplica do friso do Parténon).

$\mathrm{O}$ acontecimento, porém, mais marcante desta sua primeira visita ao Porto foi certamente o encontro com Fernando Távora. Ficámos a sabê-lo porque, em Una vita da architetto, o integra entre

[...] aquelas raras personagens, já difíceis de encontrar, pessoas preciosíssimas cujo cunho creio se perdeu (também Rogers naturalmente está entre elas), a quem devolvo toda a minha gratidão por ter podido encontrá-las (por vezes, por acaso, como certos livros preciosos) e que têm sempre toda a minha admiração, precisamente por serem tão distintas de todas as outras pessoas que conheci; abertos e curiosos em relação a tudo, dispostos a dar tudo o que é seu, não necessariamente arquitectos, $[\ldots]$ alguns mais próximos, outros mais afastados no tempo, mas todos igualmente presentes e importantes na minha vida, ainda que, por vezes, o encontro tenha sido brevíssimo, [...] como Fernando Távora no Porto ou Saenz de Oiza em La Granja (de quem, como velho racionalista, não posso deixar de citar o hilariante "O ra- 
cionalismo é aquela arquitectura moderna que tem razão!"), cada qual ao seu modo, único pela sua extraordinária humanidade tão manifesta e de que era tão fácil tirar proveito. ${ }^{16}$

Desta sua passagem pelo Porto, ficaram também marcas no modo como alguns arquitectos portugueses passaram a ler, na palavra escrita de Grassi, temas de projecto e temas de investigação particularmente pertinentes e ajustados à atmosfera arquitectónica portuguesa. Na Escola do Porto, Francisco Barata, Carlos Machado, Madalena Pinto da Silva e Rui Mealha, na Escola de Coimbra, José António Bandeirinha, Jorge Figueira ${ }^{17}$ e Paulo Providência foram, sem dúvida, leitores prospectivos da sua teoria de projecto, o que se sente no modo como todos eles, cada um à sua maneira, citaram e sublinharam alguns dos aspectos mais decisivos do seu pensamento arquitectónico. De entre os estudantes que então assistiram à conferência de Grassi, de entre todos nós (os que então assistimos ao 'discurso de Grassi'), Nuno Brandão Costa parece ter sido aquele que mais consistentemente pôs em

${ }^{16}$ Giorgio Grassi, Una vita da architetto, p. 58.

${ }^{17}$ Exemplificaremos através da seguinte passagem: "A revisitação da conferência de Giorgio Grassi permitiu repensar uma das figuras mais presentes de uma certa Escola do Porto. Sendo uma obra e um personagem distante nos dias líquidos que correm, o compromisso moral de Grassi teve ressonância numa certa Escola, mas nos anos 90 passou a ser cada vez mais marginal. Enquanto Rossi se 'perdeu' na América, Grassi permaneceu como a face mais austera do neo-racionalismo, e isso foi importante para quem acalentava uma visão 'disciplinar' da arquitectura. Os desenhos fortes, dramáticos, terminais, que apresentou são ainda hoje - ou, talvez, hoje mais do que nunca - impressionantes. A apresentação de Francisco Barata permitiu perceber a metodologia projectual de Grassi, o seu permanente reenvio para a história da cidade e do contexto, numa permanente crítica dos processos oitocentistas de reformulação viária; 'sempre muito crítico da necessidade de fazer novo, de estar sempre a inventar'. Francisco Barata fala por isso de um entendimento da 'arquitectura como missão'; a génese do projecto como 'comentário histórico' ou 'juízo sobre os lugares', que vê reflectidas na abordagem de arquitectos portugueses como Távora, Siza, Alves Costa ou Sergio Fernandez" (Jorge Figueira, Artecapital, http://www.artecapital.net/arq_des-60-osproximos-20-anos-notas-sobre-os-discursos-re-visitados-; consultado em 22-05-2017). 
prática essa teoria de projecto na sua própria obra, em particular na Biblioteca Municipal de Caminha e na reabilitação do Bairro de São João de Deus no Porto (em curso).

\section{ENSAIO SOBRE O TIPO}

Em Barcelona, a questão tipológica tinha atraído a atenção de Carlos Martí Arís que assim decide dedicar a sua investigação de doutoramento a essa matéria sensível. Não por coincidência, o orientador científico desta tese foi Giorgio Grassi. A tese, apresentada em 1988 com o título Las variaciones de la identidad, recebe o subtítulo de Ensayo sobre el tipo en arquitectura. Na verdade, é duplamente polémica na academia portuguesa de então: é demasiado sintética (pequena, nas palavras de alguns) para a ocasiāo e, por outro lado, aberta e declaradamente ensaística, logo desde o subtítulo, renunciando não só ao carácter científico que a palavra tese transporta consigo, como também ao carácter dito original (se possível inédito e nunca antes visto) a que a ciência sempre supostamente aspira, mas que compreensivelmente uma arquitectura da tradição nunca pode definitivamente alcançar.

Deste problema - de que a Escola do Porto não conseguiu, por ora, com naturalidade sair - Grassi dará conta na introdução ao livro de Martí, aquando da sua publicação:

A tese de doutoramento de Carlos Martí Arís, pela originalidade dos seus argumentos teóricos, representa uma contribuição notável para o debate teórico em torno da noção de tipo em arquitectura. [...]. Quem esperaria, dado o tema, um discurso douto, conceptual, de certo modo exaustivo, "académico", talvez fique decepcionado [...]. Este texto pode apenas completar-se coerentemente com a paralela investigação projectual do seu autor. [...] A última palavra não pode ser outra que o próprio projecto. ${ }^{18}$

${ }^{18}$ Em Carlos Martí Arís, Las variaciones de la identidad. Ensayo sobre el tipo en arquitectura, p. 7. 
A passagem citada, deve sublinhar-se, corresponde ao parecer científico que Grassi remeteu ao júri da prova. Nela se pode ler o incómodo, ainda hoje não sanado, de um arquitecto cuja tese de doutoramento trabalha a partir dos mesmos instrumentos que pautam a sua prática de projecto e que, na verdade, impedem uma leitura da investigação em arquitectura, como se esta fosse ciência stricto sensu, ou história, ou teoria pura (não contaminada por exemplos), etc. Esta linha de orientação de trabalhos doutorais teve bastante influência no modo como muitos de nós, na Escola do Porto, encaminharam as suas investigações neste âmbito. Carlos Martí Arís veio ao Porto dissertar sobre o assunto e foi mesmo o orientador científico de Carlos Machado e de Madalena Pinto da Silva que assim tiveram o privilégio de verem os seus trabalhos orientados numa direcção que o próprio Grassi, como orientador de Martí, permitiu, apesar das resistências ${ }^{19}$.

\section{Segunda conferência no Porto: Sagunto (1999)}

Em 1999, Grassi regressou ao Porto ${ }^{20}$ para uma conferência integrada no ciclo Construir no Tempo. Tinha publicado uma monografia da sua obra na Electa (1996), com uma introdução de Juan José Lahuerta intitulada "O arquitecto e os seus modelos" - título que, significativamente, Grassi quase reproduziu na sua última conferência no Porto $\left(\right.$ em 2015) ${ }^{21}$. Este evento contava igualmente com Eduardo Souto Moura e Rafael Moneo. Entre outras intervenções em pré-existências construídas, Grassi mostrou Sagunto, uma obra cujo

\footnotetext{
${ }^{19}$ Carlos Martí publicou os referidos pareceres científicos em: Carlos Martí Arís, Cabos sueltos, Madrid, Lampreave, 2012, pp. 193-205.

${ }^{20}$ Grassi regressou ao Porto a convite de Michele Cannatà e Fátima Fernandes, organizadores do ciclo de conferências Construir no Tempo. Ver Construir no tempo, coord. Fátima Fernandes, Michele Cannatà, Lisboa, Estar, 1999.

${ }^{21}$ Giorgio Grassi. I progetti, le opere e gli scritti, intr. Juan José Lahuerta, Milano, Electa, 1996.
} 
projecto se iniciou em 1985 e cujo projecto de execução (em co-autoria com Manuel Portaceli) se estendeu até 1992.

Esta obra cedo interessou o milieu arquitectónico português na medida em que colocava o problema da intervenção no património de um modo desassombrado, sem complexos patrimonialistas, mas também com um profundo conhecimento e respeito pelo passado romano daquela arquitectura, com um posicionamento que, a nosso ver, nos mostrava, de modo claro, a concretização de algumas ideias que Távora e Siza (sobretudo no projecto para o Chiado) deixavam adivinhar. Provavelmente, Grassi foi convidado a integrar o ciclo justamente por causa de Sagunto e a verdade é que ainda estávamos longe do lamentável final de um processo que conduziu a uma ordem de demolição da intervenção de Grassi e Portaceli pelo Supremo Tribunal de Justiça Espanhol que desta feita confirmava a sentença do Tribunal da Comunidade Valenciana.

O facto de Grassi recuperar o uso teatral da ruína, propondo uma intervenção na ruína romana de um teatro que pressupunha a recuperação do seu uso ou função originária, ou seja, o facto de recuperar o teatro como era, para recriar um teatro romano onde encenar teatro hoje (aspecto da intervenção a que Pedro Alarcão dedicou uma boa parte da sua investigação de doutoramento ${ }^{22}$ ) constituiu uma ocasião única para a disciplina se confrontar com a arquitectura do passado, sem preconceitos de qualquer ordem (nem mesmo aquele preconceito que atribui aos antigos uma espécie de auctoritas por antiguidade ou vetustez que impede as construçôes antigas de recuperarem a sua utilitas inicial ou, se quisermos, original).

Eduardo Souto de Moura reinterpretou o projecto de Sagunto, à sua maneira, sendo que os seus projectos implicavam pré-existências construídas com valor patrimonial: San-

${ }^{22}$ Construir na ruina, a propósito da cidade romanizada de Conimbriga, Porto, FAUP, 2009 (policopiado). 


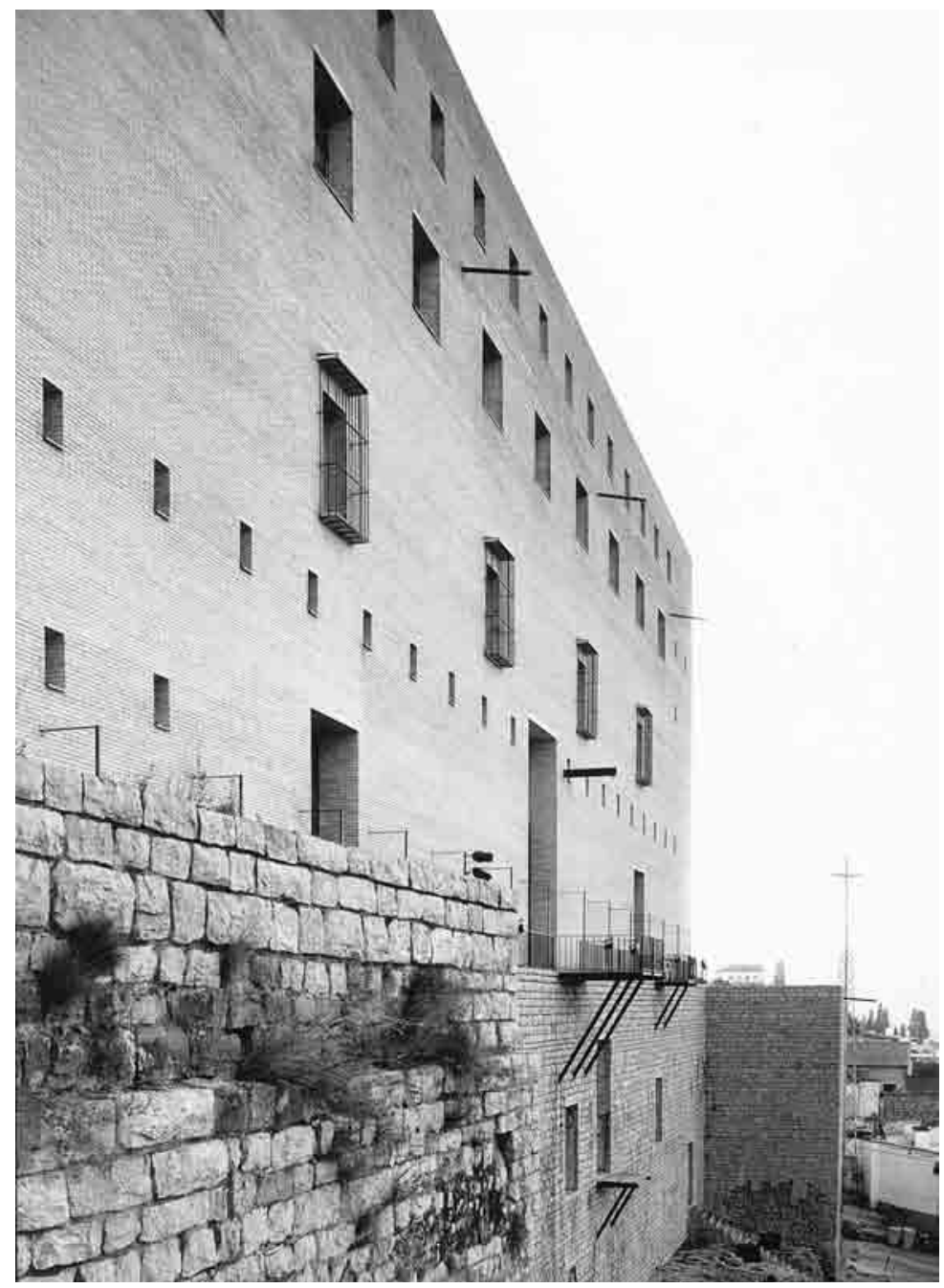

Fig. 3 Giorgio Grassi, Teatro romano, Sagunto, (1985) 1990-1993. (C Giorgio Grassi.

ta Maria do Bouro, Alfândega do Porto, Bernardas de Tavira, etc. $\mathrm{Na}$ realidade, na sua conferência intitulada $O$ que aprendi com a arquitectura?, proferida a propósito do octogésimo aniversário da revista Casabella, Souto Moura organiza a sua 
aprendizagem alfabeticamente "de Z a A" e, ao chegar à letra "G", admite dever a Giorgio Grassi a sua forma de encarar a intervenção no património ${ }^{23}$.

\section{Terceira conferênCia no Porto: Alberti (2015)}

Quando Grassi regressou ao Porto pela última vez, em 2015²4, para lançar o primeiro livro, Leon Batista Alberti e a arquitectura romana, de uma colecção dedicada à tradução da sua obra escrita completa, intitulada Giorgio Grassi, opera omnia sic ${ }^{25}$, Souto Moura, ao fazer a apresentação introdutória de Grassi, falou com muito entusiasmo, na presença do autor, daquilo que liga a sua obra à de Grassi. As suas palavras, que fizeram lembrar um título de Nietzsche que Grassi certamente não recusaria, $O$ que devo aos antigos, pareciam, neste caso, consubstanciar a questão análoga: $O$ que devo eu (Souto Moura) a Giorgio Grassi (e à sua teoria de projecto, evidentemente). A nosso ver, aquilo a que o milieu arquitectónico português (e, em particular, do Porto) pôde assistir, foi a confirmação pública do que Souto Moura vinha anunciando em conferências e entrevistas e que, também na nossa perspectiva, nos permitiu afirmar que se poderia dizer, sem exagero, que Giorgio Grassi era o arquitecto contemporâneo que melhor e mais decididamente tinha enfrentado o problema do movimento moderno, sem cair na euforia da vanguarda, nem na nostalgia típica de antiquário. Essa sua posição (difícil porquanto incompreendida por uns e por outros), apesar de particularmente importante nos anos oitenta do século passado, pensamos, e dissemos na altura, mantém toda a sua pertinência no momento actual de enorme dificuldade da arquitectura

${ }^{23}$ Cf. Souto Moura, Eduardo Souto Moura | em trânsito \#22, https://vimeo. com/18320317 (consultado em 23-05-2017).

${ }^{24}$ Grassi proferiu uma conferência intitulada L'oggetto del progetto e il suo modello.

${ }^{25}$ Projecto de tradução para português da obra escrita de Giorgio Grassi: Afrontamento, FIMS, coord. José Miguel Rodrigues (em curso). 
portuguesa em Portugal e, desde há alguns anos, igualmente, da arquitectura portuguesa no estrangeiro (dada a recente diáspora de arquitectos portugueses pelo mundo).

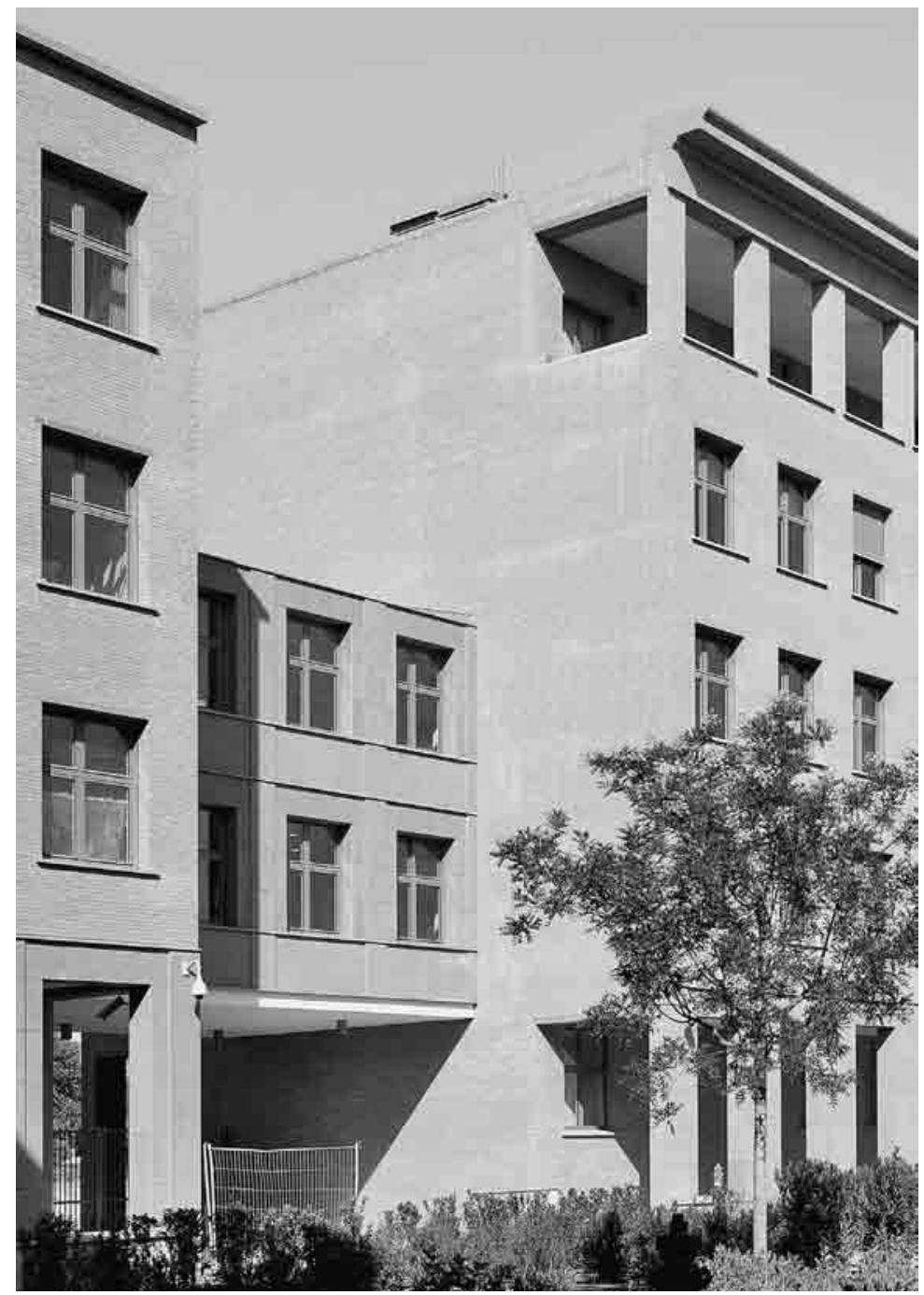

Fig. 4 Giorgio Grassi, Cassa di Risparmio, Florença. () Giorgio Grassi. 
Dissemos, também então, e gostaríamos de concluir este ensaio da mesma forma, que, independentemente de "quem teve a ideia primeiro" 26 (um aforismo de Karl Kraus a que Grassi se referirá em Alberti e a arquitectura romana), basta observar o pátio da Escola Superior de Educação em Setúbal ou o mais conhecido Pavilhão de Portugal no recinto da Expo (curiosamente o seu lado menos monumental), para percebermos como a paixão de Grassi por uma personagem tão maltratada e malbaratado pela história, como Heinrich Tessenow, encontrou em Álvaro Siza um aliado inequívoco, e a nosso ver de peso, dada a grande qualidade daquelas suas duas obras em particular.

${ }^{26}$ Giorgio Grassi, Leon Battista Alberti e a arquitectura romana, trad., notas, intr. José Miguel Rodrigues, Porto, Afrontamento, FIMS, 2015, p. 177. 